\title{
§9. Influence of Dissolved Gas Concentra- tion on Subcooled Flow Boiling Critical Heat Flux in Short Vertical Tube
}

Hata, K. (Inst. of Advanced Energy, Kyoto Univ.) Komori, H. (Dept. of Eng. Sci. and Tech., Kyoto Univ.)

Shiotsu, M. (Dept. of Eng. Sci. and Tech., Kyoto Univ.)

Noda, $N$.

The subcooled flow boiling critical heat fluxes (CHFs) are systematically measured by using the water loop installed the pressurizer to investigate the pressurization gas effect and the dissolved gas concentration for the flow velocities $(u=4.0$ to $13.3 \mathrm{~m} / \mathrm{s})$, the inlet subcoolings $\left(\Delta T_{\text {sub,in }}=70.08\right.$ to $\left.153.87 \mathrm{~K}\right)$, the inlet pressure $\left(P_{\text {in }}=740.67\right.$ to $975.78 \mathrm{kPa}$ ) and the dissolved oxygen concentration $(O=6.59$ to $0.0265 \mathrm{ppm})$ [1]. The SUS304 tube of the inner diameter $(d=3 \mathrm{~mm})$, the heated length $(L=66.5 \mathrm{~mm})$ and $L / d=22.17$ with the inner surface of rough finished was used.

\section{Literature review}

Hata et al. [2-4] have clarified that the $q_{c r s u b}$ against $\Delta T_{\text {sub,out }}$ for $\Delta T_{\text {subou }} \geq 30 \mathrm{~K}$ are almost proportional to $d^{0.4}$ and $u^{0.4}$ for fixed $\Delta T_{\text {sub.out }}$ and $L / d$, to $\left(\Delta T_{\text {sub,out }}\right)^{0.7}$ for a fixed $L / d$ and to $(L / d)^{-0 . I}$ for a fixed $\Delta T_{\text {sub,out }}$ based on the experimental data under the $\mathrm{N}_{2}$ gas pressure. And, the following CHF correlations against outlet and inlet subcoolings [2-4] have been given.

$$
\begin{aligned}
& B o=0.082\left\{\frac{d}{\sqrt{\sigma / g\left(\rho_{t}-\rho_{g}\right.}}\right\}^{-0.1} W e^{-0.3}\left(\frac{L}{d}\right)^{-0.1} S c^{0.7} \\
& \text { for outlet subcooling }\left(\Delta T_{\text {sub out }} \geq 30 \mathrm{~K}\right) \\
& B o=C_{I}\left\{\frac{d}{\sqrt{\sigma / g\left(\rho_{l}-\rho_{g}\right)}}\right\}^{-0.1} W e^{-0.3}\left(\frac{L}{d}\right)^{-0.1} e^{-\frac{(L / d)}{C_{2} R e^{0.4}}} S c^{*} c_{3}
\end{aligned}
$$

$$
\text { for inlet subcooling }\left(\Delta T_{\text {sub,in }} \geq 40 \mathrm{~K}\right)
$$

where, $C_{1}=0.082, C_{2}=0.53$ and $C_{3}=0.7$ for $L / d \leq$ around 40

$$
C_{1}=0.092, C_{2}=0.85 \text { and } C_{3}=0.9 \text { for } L / d>\text { around } 40
$$

\section{CHFs under the saturated vapor pressurization by the} pressurizer

The CHF, $q_{c r, s u b}$, at the outlet pressure of around 800 $\mathrm{kPa}$ are shown versus the outlet subcoolings measured, $\Delta T_{\text {sub,out }}$, with the flow velocity as a parameter in Fig. 1 . The dissolved oxygen concentration of test water in the loop was $6.59 \mathrm{ppm}$ before this experiment. The test tube with rough finished inner surface was used similar to that under the $\mathrm{N}_{2}$

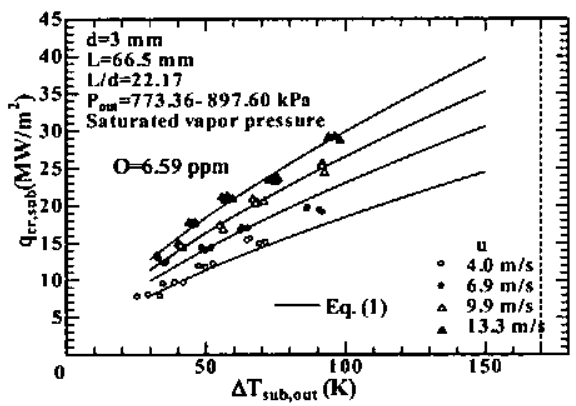

Fig. $1 q_{c r, s u b}$ vs. $\Delta T_{\text {sub,out }}$ for $d=3 \mathrm{~mm}$ with $L=66.5 \mathrm{~mm}$ at $P_{\text {ow }}=773-897 \mathrm{kPa}$.

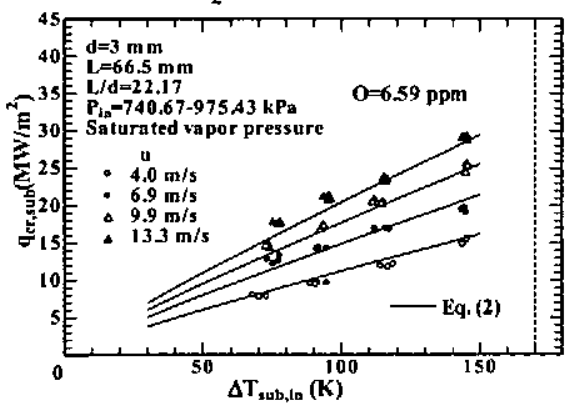

Fig. $2 q_{\text {cr.sub }}$ vs. $\Delta T_{s u b \text { in }}$ for $d=3 \mathrm{~mm}$ with $L=66.5 \mathrm{~mm}$ at $P_{i n}=740-975 \mathrm{kPa}$. gas pressure previously obtained. The CHF become higher with an increase in flow velocity at a fixed $\Delta T_{\text {sub.our }}$. This figure illustrates the trends in the variation of $\mathrm{CHF}$ with increasing outlet subcooling. The CHF for the $\Delta T_{\text {subout }}$ greater than around $30 \mathrm{~K}$ increase with an increase in $\Delta T_{\text {sub,our. }}$. The increasing rate becomes lower for higher $\Delta T_{\text {subout }}$. The curves given by Eq. (1) at each flow velocity are shown in Fig. 1 for comparison. The CHF data for $\Delta T_{\text {subout }} \geq 30 \mathrm{~K}$ are in good agreement with the values given by Eq. (1): This CHF correlation was derived based on these experimental data for $L / d$ range from 4.08 to 74.85 under the $\mathrm{N}_{2}$ gas pressure [2-4].

The relation between $q_{c r, s u b}$ and $\Delta T_{\text {sub,out }}$ shown in Fig. 1 is rewritten on $q_{c r, s u b}$ vs. $\Delta T_{s u b . i n}$ graph in Fig. 2 to know the influence of $\Delta T_{\text {sub,in }}$ on $\mathrm{CHF}$ for flow velocities from 4.0 to $13.3 \mathrm{~m} / \mathrm{s}$. The values of CHF data show nearly the same trends of dependence on $\Delta T_{\text {sub.out }}$ although the value of $\Delta T_{\text {subin }}$ for each CHF data is far higher than that of $\Delta T_{\text {sub,out }}$. The curves derived from CHF correlation against inlet subcooling, Eq. (2), also based on the experimental data under the $\mathrm{N}_{2}$ gas pressure previously obtained are shown at each flow velocity for comparison in Fig. 2. The CHF data are in good agreement with the values given by Eq. (2) in the whole experimental range.

\section{Influence of dissolved gas concentration}

The $q_{\text {crsub }}$ at the outlet pressure of around $800 \mathrm{kPa}$ are measured for the dissolved oxygen concentration, $O$, of 6.59 to $0.0265 \mathrm{ppm}$ with the flow velocities of 4.0 to $13.3 \mathrm{~m} / \mathrm{s}$. Figure 3 shows the relation between the $q_{c r s u b}$ and the dissolved oxygen concentration for $\Delta T_{\text {sub.in }}=145 \mathrm{~K}$ (liquid temperature of around $298 \mathrm{~K}$ ) with the rough finished inner surface test tube. The $q_{\text {cr,sub }}$ keeps almost constant for the dissolved oxygen concentrations ranging from $6.59 \mathrm{ppm}$ (around saturated condition) to $0.0265 \mathrm{ppm}$ for each flow velocity. The corresponding curves for each flow velocity obtained from the CHF correlation against inlet subcooling, Eq. (2), were also shown in the figure. The $q_{c r, s u b}$ in the whole experimental range appear to be well expressed by $\mathrm{Eq}$ (2). However, the $q_{c r . s u b}$ data for higher flow velocities at the lowest dissolved oxygen content seem to be slightly lower than those for higher concentrations.

Reference

1) Hata K. et al., Paper No. ICONE 12-49194, (2004) 1

2) Hata K. et al., Paper No. NURETH10-C00207, (2003) 1

3) Hata K. et al., Journal of Heat Transfer, Trans. ASME, Series C 126, (2004) 312

4) Hata K. et al., JSME International Journal, Series B 47, (2004) 306

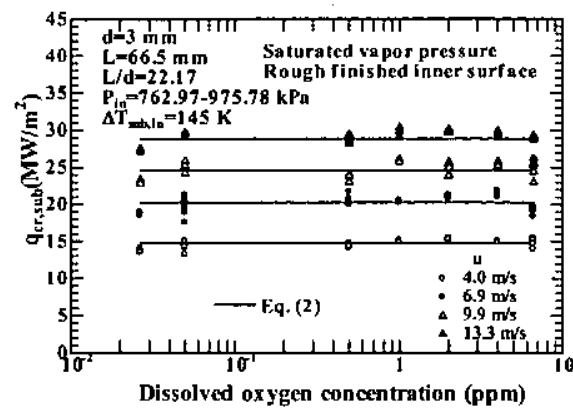

Fig. $3 q_{c r, s u b}$ for $d=3 \mathrm{~mm}$ with $O=0,0265$ $6.59 \mathrm{ppm}$. 